\title{
Magnetically retrievable $\mathrm{Rh}(0)$ nanocomposite as relevant catalyst for mild hydrogenation of functionalized arenes in water.
}

Carl-Hugo Pélisson, Audrey Denicourt-Nowicki, * and Alain Roucoux*

ENSCR, UMR, CNRS 6226, 11 Allée de Beaulieu, CS 50837, 35708 Rennes Cedex 7, France

Audrey.Denicourt@ensc-rennes.fr; Alain.Roucoux@ensc-rennes.fr

Total Pages : 7

No of Supplementary Figures : $\quad 7$ 


\section{Experimental}

\section{Chemicals}

$\mathrm{FeCl}_{2} \cdot 4 \mathrm{H}_{2} \mathrm{O}, \mathrm{FeCl}_{3} \cdot 6 \mathrm{H}_{2} \mathrm{O}$, and $\mathrm{RhCl}_{3} \cdot 3 \mathrm{H}_{2} \mathrm{O}$ were purchased from Strem Chemicals. Sodium borohydride and all organic substrates were obtained from Aldrich, Acros or Alfa Aesar and were used as received without further purification. Water was distilled twice before use by conventional methods.

\section{Characterizations}

The prepared magnetic nanocatalysts were characterized by Transmission Electron Microscopy analyses (JEOL TEM 100CXII electron microscope operated at an acceleration voltage of $100 \mathrm{kV}$ - Université Pierre et Marie Curie). The nanomaterial was dispersed in ethanol or water with ultrasounds and a drop of this solution was deposited on a carbon-coated copper grid and dried in air.

XPS measurements were performed at the Institut Physique de Rennes (UMR UR1-CNRS 6251) with a Mg K x-ray source $(\mathrm{hv}=1254 \mathrm{eV})$, using a VSW HA100 photoelectron spectrometer with a hemispherical photoelectron analyzer, working at an energy pass of $22 \mathrm{eV}$. The experimental resolution was then $1.0 \mathrm{eV}$. The binding energies were referenced to the photopeak $\mathrm{C} 1 \mathrm{~s}$ at $285.0 \mathrm{eV}$. The decomposition of the Rh $3 \mathrm{~d}$ photopeak was achieved according to a Gaussian/ Lorentzian ratio equal to 0.3 and accounting for the difference in binding energy levels between both signals as constraints. ICP-AES analyses were performed at the Institut des Sciences Analytiques (ISA) of CNRS in Villeurbanne.

\section{Synthesis of $\gamma-\mathrm{Fe}_{2} \mathrm{O}_{3} \mathrm{NPs}$.}

$\gamma-\mathrm{Fe}_{2} \mathrm{O}_{3}$ particles were prepared according to the classical procedure by coprecipitation, as previously described. ${ }^{28}$ Ferrous chloride hydrate $(2.6 \mathrm{~g}, 13 \mathrm{mmol})$ was added to a hydrochloric acid solution $(20 \mathrm{~mL}, 2 \mathrm{M})$. Then, ferric chloride hydrate $(7.1 \mathrm{~g}, 26 \mathrm{mmol})$ was dissolved in nitrogen-purged water $(200 \mathrm{~mL})$, followed by the addition of the ferrous chloride solution. After mechanically stirring for $15 \mathrm{~min}, 20 \mathrm{~mL}$ of a nitrogen-purged aqueous $\mathrm{NH}_{3}$ solution $(20 \% \mathrm{wt})$ were slowly introduced. The color of the solution turned from orange to deep dark brown. The 
stirring was maintained for $1 \mathrm{~h}$. The nanoparticles were magnetically decanted and washed with large amounts of deionized water repeatedly.

\section{Synthesis of $\mathrm{Rh}^{0} @ \gamma-\mathrm{Fe}_{2} \mathrm{O}_{3}$ nanocomposite.}

After redispersion of maghemite $(1 \mathrm{~g})$ in deionized water $(50 \mathrm{~mL})$ by sonication, the $\mathrm{pH}$ was adjusted over 11 through addition of a $\mathrm{NaOH}$ solution $(1 \mathrm{M})$. An aqueous solution of $\mathrm{RhCl}_{3} .3 \mathrm{H}_{2} \mathrm{O}\left(26 \mathrm{mg}, 9.7 \times 10^{-6} \mathrm{~mol}, 10 \mathrm{~mL}\right)$ was slowly added and the stirring was maintained for $1 \mathrm{~h}$. After cooling at $0^{\circ} \mathrm{C}$, an aqueous solution of $\mathrm{NaBH}_{4}\left(1 \mathrm{mg}, 2.6 \times 10^{-5} \mathrm{~mol}, 10 \mathrm{~mL}\right)$ was added dropwise. After $30 \mathrm{~min}$ at $0^{\circ} \mathrm{C}$, the solution was stirred at room temperature for $2 \mathrm{~h}$. The nanoparticles were magnetically decanted, washed with deionized water, and dried at $80^{\circ} \mathrm{C}$ overnight. $\mathrm{Pd}^{0} @ \gamma-\mathrm{Fe}_{2} \mathrm{O}_{3}$ nanocomposite was prepared following the same methodology, and as recently reported. ${ }^{28}$

\section{Hydrogenation experiments and recycling tests.}

The catalyst $\left(50 \mathrm{mg}, 4.8 \times 10^{-6} \mathrm{~mol}\right)$ was introduced in a glass recipient with a stirring bar and redispersed in deionized water $(10 \mathrm{~mL})$ by sonication. The reactor was connected with a gas burette $(500 \mathrm{~mL})$ with a flask to balance the pressure. The adequate quantity of substrate $\left(4.8 \times 10^{-4} \mathrm{~mol}\right)$ was added. The solution was put under vacuum, followed by hydrogen. The operation was renewed 3 times and the final pressure of hydrogen was adjusted to 1 bar $\mathrm{H}_{2}$. The reaction was monitored by the volume of gas consumed. At the end of the reaction, the catalyst was recycled by applying a neodymium magnet under the recipient to precipitate magnetically the catalyst. The aqueous reaction mixture was removed and extracted with diethyl ether $(3 \times 2$ $\mathrm{mL})$. The catalyst was washed with deonized water and precipitated 3 times before a new run.

Conversions were determined from Gas Chromatography using a Trace GC Ultra (Thermo Scientific) apparatus with a FID Detector, equipped with a GC ThermoFischer TR5 capillary column (30 m, 0.25 i.d.), with $\mathrm{N}_{2}$ as vector gas. The injector and detector temperatures were set at $250^{\circ} \mathrm{C}$. Products identification was performed by comparison of their retention times with commercial pure products.

The TOF values were calculated for a complete conversion of the substrate (checked by GC analyses) and defined as number of consumed $\mathrm{H}_{2}$ (on the basis of at least $3 \mathrm{H}_{2}$ for aromatic ring) per mol of introduced Rh per hour. 
2. X-Ray Diffractogram of $\gamma-\mathrm{Fe}_{2} \mathrm{O}_{3} \mathrm{NPs}$.

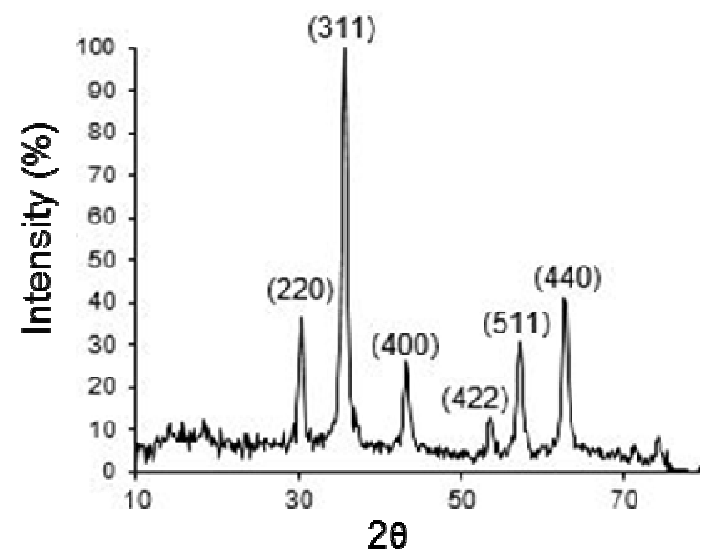

Fig S1. XRD pattern of $\gamma-\mathrm{Fe}_{2} \mathrm{O}_{3} \mathrm{NPs}$

3. X-ray Photoelectron Spectrum of $\gamma$-Fe $\mathrm{Fe}_{2} \mathrm{O}_{3} \mathrm{NPs}$.

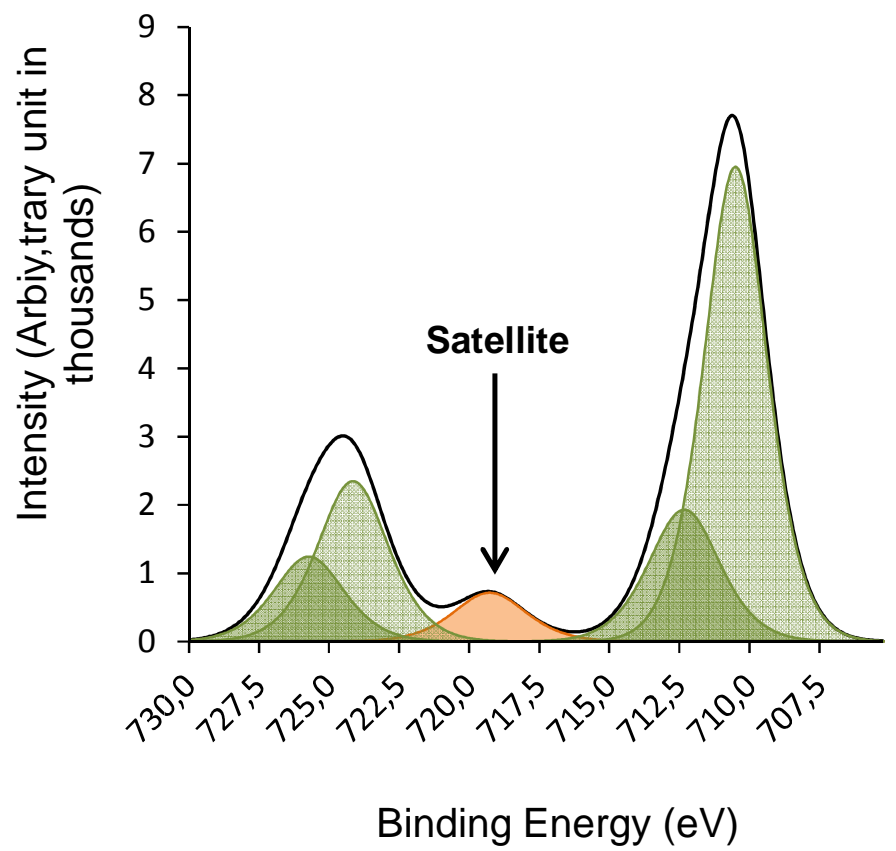

Fig S2. X-ray Photoelectron spectrum of $\gamma-\mathrm{Fe}_{2} \mathrm{O}_{3} \mathrm{NPs}$ 
4. ${ }^{57} \mathrm{Fe}$ Mössbauer Spectrum of $\gamma-\mathrm{Fe}_{2} \mathrm{O}_{3} \mathrm{NPs}$.

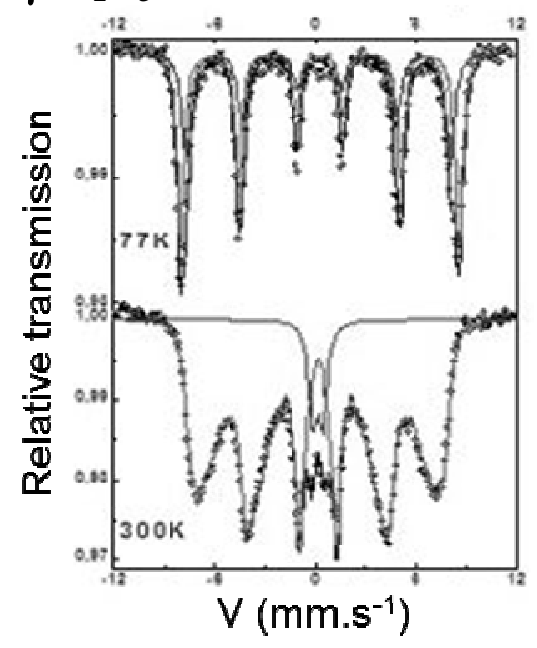

Fig S3. ${ }^{57} \mathrm{Fe}$ Mössbauer spectrum of $\gamma$ - $\mathrm{Fe}_{2} \mathrm{O}_{3}$ particles

5. Magnetization curve of $\gamma-\mathrm{Fe}_{2} \mathrm{O}_{3} \mathrm{NPs}$ at $300 \mathrm{~K}$ (Msat = Saturation magnetization, $\mathrm{Hc}=$ coercive force $)$.

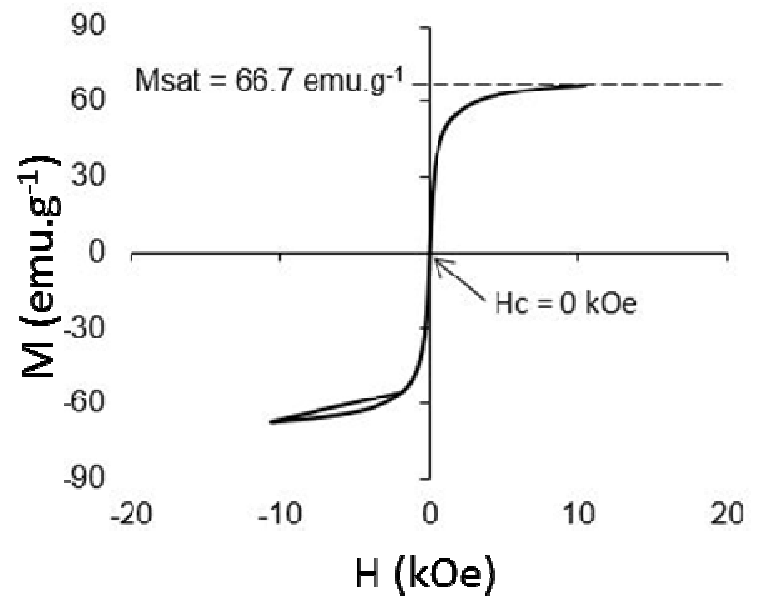

Fig S4. Magnetization curve of $\gamma-\mathrm{Fe}_{2} \mathrm{O}_{3}$ particles at $300 \mathrm{~K}$

$($ Msat $=$ Saturation magnetization, $\mathrm{Hc}=$ coercive force $)$ 


\section{TEM analysis and size distribution of $\mathrm{Rh}^{0} @ \gamma-\mathrm{Fe}_{2} \mathrm{O}_{3}$}
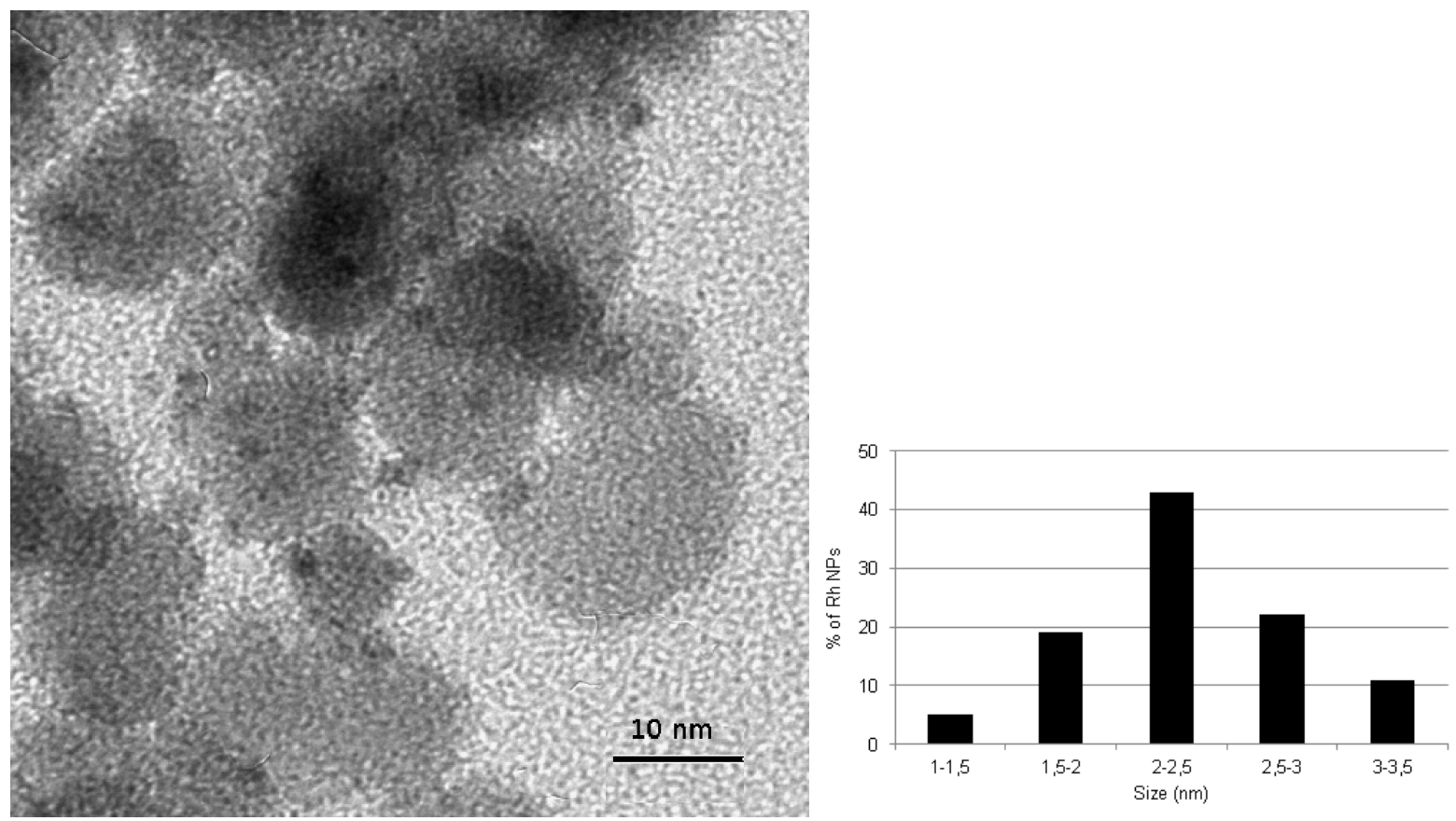

Fig S5. (a) TEM picture (Scale Bar $=10 \mathrm{~nm})$ of $\mathrm{Rh}^{0} @ \gamma-\mathrm{Fe}_{2} \mathrm{O}_{3}$, (b) Size distribution of $\mathrm{Rh}^{0} \mathrm{NPs}$,

7. X-ray Photoelectron Spectrum of $\mathrm{Rh}^{0} @ \gamma-\mathrm{Fe}_{2} \mathrm{O}_{3} \mathrm{NPs}$.

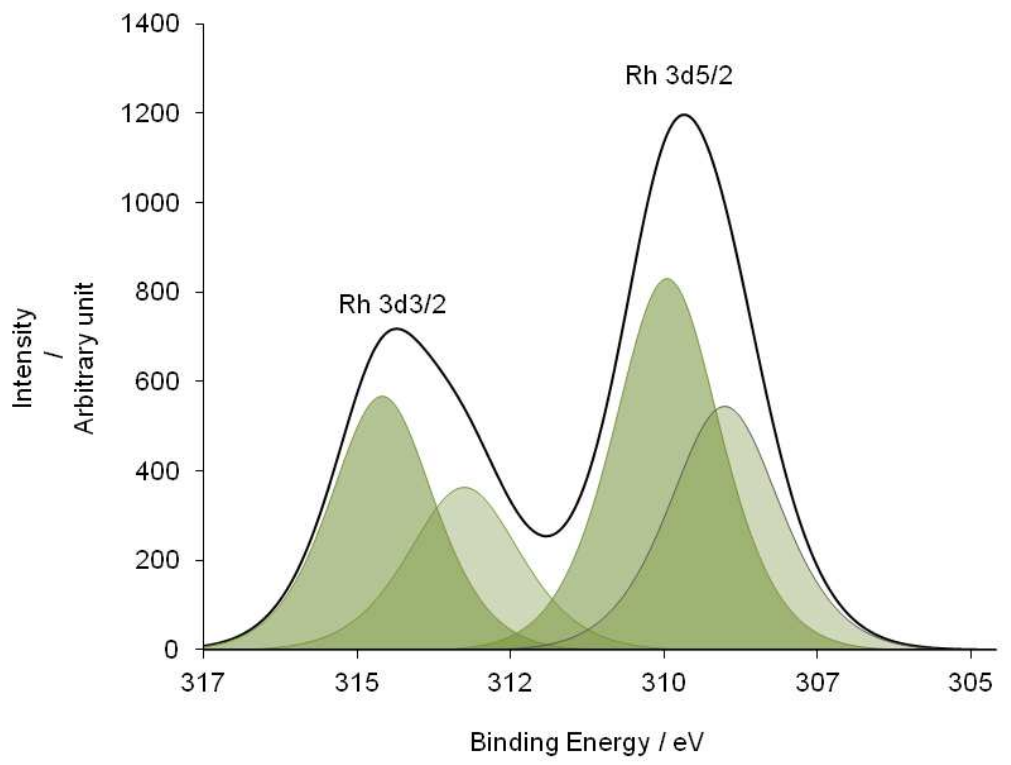

Fig S6. X-ray photoelectron spectrum of $\mathrm{Rh} 3 \mathrm{~d}$ of $\mathrm{Rh}^{0} @ \gamma-\mathrm{Fe}_{2} \mathrm{O}_{3}$ nanocomposite. 
8. Kinetics of the tandem hydrogenation-dechlorination reaction of 4-chloronitrobenzene with $\mathrm{Rh}^{0} @ \gamma-\mathrm{Fe}_{2} \mathrm{O}_{3}$ nanocomposite.

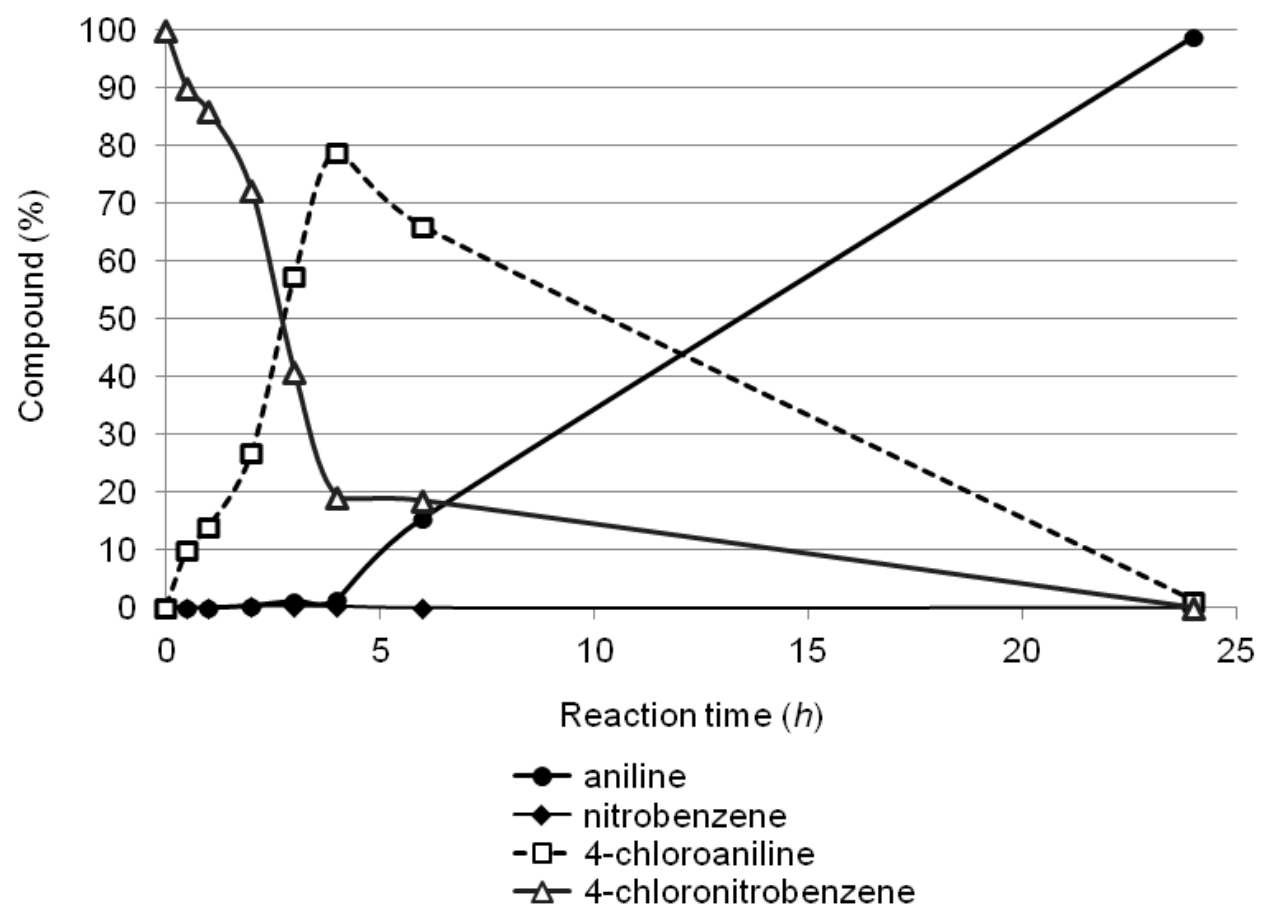

Fig S7. Tandem hydrogenation-dechlorination reaction of 4-chloronitrobenzene with $\mathrm{Rh}^{0} @ \gamma-\mathrm{Fe}_{2} \mathrm{O}_{3}$ nanocomposite 